\title{
Short-term changes in responsiveness to models in Betta splendens
}

\author{
DAVID F. CHANTREY \\ University of Keele, Keele, Staffs. STS $5 B G$, England
}

\begin{abstract}
In an experiment attempting a detailed analysis of the habituation of aggression in blue male Siamese fighting fish, the fish viewed their mirror images for varying lengths of time, and then the duration of gill-cover erection was measured during a 60 -sec presentation of a simplified model. Tests were separated by $24 \mathrm{~h}$. Responsiveness was lower on the first day of testing than on any subsequent day. There was a peak of responsiveness to a blue model following 5-sec mirror exposure, with a decline in responsiveness after longer mirror exposures. Mirror exposure did not affect responsiveness to a green model. These results suggest that there are incremental and decremental effects of responding in this situation, both of which are stimulus-specific.
\end{abstract}

Many studies have shown that the aggressive display of some species of fish wanes during long-term exposure to the eliciting stimulus (e.g., for fighting fish: Baenninger, 1966; Clayton \& Hinde, 1968; Figler, 1972; Meliska \& Meliska, 1976; and Peeke \& Peeke, 1970; for sticklebacks: Assem \& Molen, 1969; and Peeke \& Veno, 1976; and for convict cichlids: Gallagher, Herz, \& Peeke, 1972). Most of these studies have used prolonged exposure to a live conspecific or to a mirror image to induce habituation. However, waning of responsiveness is also obtained when relatively short periods of exposure are given at $24 \mathrm{~h}$ intervals (e.g., Figler, 1972; Meliska \& Meliska, 1976; Peeke \& Peeke, 1970).

Experiments in which models of various sorts have been used have shown that these, too, can elicit marked aggressive displays. In one of the earliest experiments of this kind. Lissman (1932) showed that the effectiveness of models in eliciting aggressive displays in fighting fish depended on the stimulus characteristics of the model. Appropriately shaped models (i.e., like a displaying male fish) with inappropriate colors would not elicit the display nearly as well as similarly shaped but appropriately colored models.

Lissman's (1932) study and an experiment reported by Simpson (1968) both suggest that the aggressive display of male fighting fish is readily elicited by model presentation. Yet, after mirror fights lasting only $1 \mathrm{~h}$, displaying to models is much harder to elicit (Chantrey, unpublished observations). Some

I am indebted to Charmian Brewin, Dr. Peter Chevins, Dr. Geoff Davies, Dr. Tony Lynch, Dr. Glyn Prosser, and Richard Waite for their criticisms of an earlier version of this paper. Requests for reprints should be sent to David F. Chantrey, Department of Psychology, University of Keele, Keele, Staffs. ST5 5BG, England. results (e.g., Baenninger, 1966) suggest that $1 \mathrm{~h}$ of fighting a live conspecific, or a mirror, results in very little waning. Also, Clayton and Hinde (1968) showed that there was very little waning during the first $26 \mathrm{~min}$ of mirror exposure on the first day in their fish. This suggests that response difference occurs much more rapidly when a fish is first exposed to a mirror and then presented with a model in an attempt to elicit the aggressive display.

The present experiment was therefore conducted to investigate the response difference in displaying to simple models after rather short periods of mirror exposure. In the light of Lissmann's (1932) experiment and the results reported by Peeke and Veno (1973), the experiment was also designed to see whether responding to a stimulus resembling the mirror reflection in color differed from responding to a stimulus differing from the mirror reflection in color.

\section{METHODS}

\section{Subjects}

Male Siamese fighting fish (Betta splendens) were obtained in batches of six from a local dealer. They were kept in individual tanks at a temperature of $25^{\circ} \pm 2{ }^{\circ} \mathrm{C}$. They were fed once a day on white-worms (which were kept in the laboratory) with an occasional supplement of commercial fish-food flakes. The fish were kept in total visual isolation from each other for at least 3 weeks before the start of testing and throughout the experiment. A total of 24 fish were used in the experiment. They were all blue in color.

\section{Procedure}

Since it was felt possible that there might be a carry-over effect from one day's testing to the next, a repeated-measures Latin square design was employed (Plan VIII in Winer, 1970, p. 549). Each fish was tested once each day for 6 days, the testing session being at about 12 noon.

The variables in the experiment were days (6), length of mirror exposure $(0,2,5,10,30$, or $300 \mathrm{sec})$, and color of model (12 fish had a blue model, the other 12 fish had a light green 
model). The models were cylinders of plasticine $5 \times 1 \mathrm{~cm}$ in diameter on a long wire "handle." The fish were tested in a prearranged, randomly determined order, though the length of mirror exposure they received was dictated by the Latin square. A different Latin square was used for each of the model-color groups.

The testing procedure for each fish was as follows. The experimenter sat approximately $70 \mathrm{~cm}$ in front of the fish's tank. When the fish was oriented towards the experimenter, the mirror was placed against the side of the tank facing the experimenter and was held in place for the predetermined time. The mirror was then removed, and after a gap of $5 \mathrm{sec}$, model presentation began. The model was presented with its long axis against the outside of the tank for a total of $60 \mathrm{sec}$, during which, when the fish was near the model end of the tank, the model was moved so as to keep as close to the fish as possible. When the fish was not at the model end of the tank, the model was moved in an arbitrary manner.

During the 60-sec model presentation, the total duration of gill-cover erection (Simpson, 1968) was measured. In the present experiment, it was decided to measure only the duration of gillcover erection, since it is possible to record this very reliably. It is also an element of the aggressive display which is reliably elicited by most mirror and model presentations. Experiments in progress are measuring other behavior patterns in this situation. Only 1 fish out of the 24 did not display gill-cover erection at all during the experiment.

\section{RESULTS}

Analysis of the Latin square design revealed that there was a highly significant effect of the length of mirror exposure on duration of gill-cover erection during model presentation $[\mathrm{F}(5,60)=4.006$, $\mathrm{p}<.01]$ (see Figure 1). There was also significantly less gill-cover erection with the green than with the blue model $[\mathrm{F}(1,12)=4.790, \mathrm{p}<.05]$ and a significant Length of Mirror Exposure by Color of Model interaction $[F(5,60)=3.594, p<.01]$. A one-way analysis of variance with repeated measures was performed on each group of fish. For the group exposed to the blue model, the effect of length of

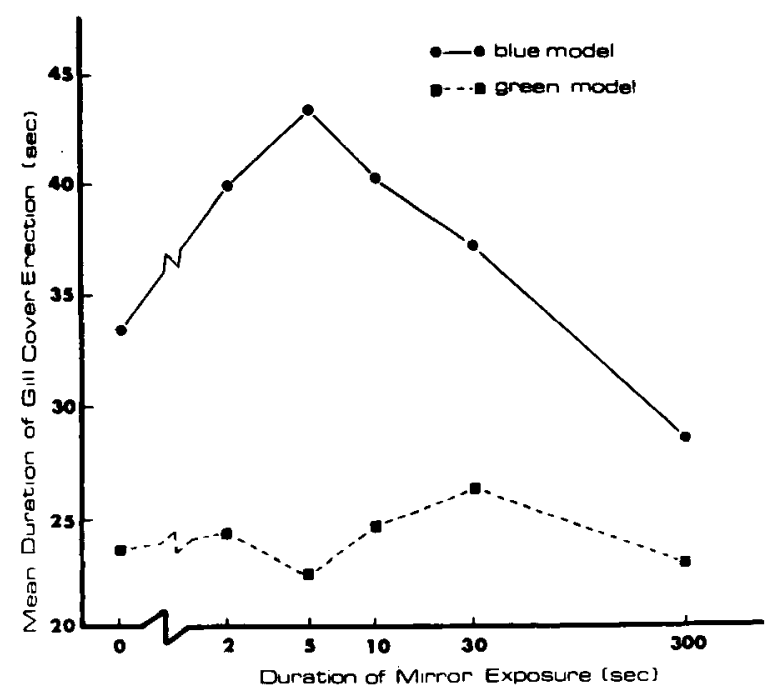

Figure 1. Mean duration of gill-cover erection in a $60-\mathrm{sec}$ test after different durations of mirror exposure and with different models. (Duration of mirror exposure is plotted on a $\log 10$ scale).

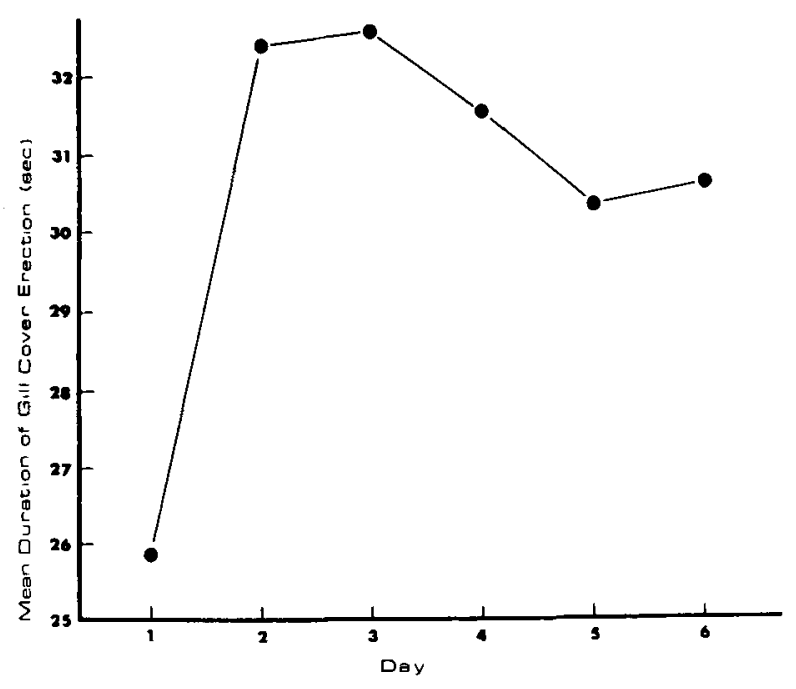

Figure 2. Mean duration of gill-cover erection in a 60-sec test on each of the 6 days of the experiment.

mirror exposure was highly significant $[F(5,25)=$ $9.340, p<.01$ ], but the length of mirror exposure had no significant influence on the duration of gillcover erection when a green model was used $(\mathrm{F}<1)$.

A Newman-Keuls test (Winer, 1970, p. 309) on the data for the blue model group showed that after 300 -sec mirror exposure, or with no mirror exposure, the duration of gill-cover erection was significantly less than at any other length of mirror exposure. Indeed, there was less gill-cover erection after 300 -sec than after 0-sec mirror presentation. The only other significant effect was that there was less gill-cover erection after 30 -sec than after 5 -sec mirror presentation. (For all significant comparisons, $\mathrm{p}<.05$.)

The initial Latin square analysis also revealed that Days was a significant factor $[F(5,60)=3.042, p<$ .05]. An analysis using the Newman-Keuls test revealed that there was less gill-cover erection on Day 1 than on any of the other days. There were no other significant differences between days (see Figure 2).

\section{DISCUSSION}

The results of the present experiment show that for a model resembling in color the mirror image of a fighting fish, there is a short-term increment in responsiveness, which peaks at about $5 \mathrm{sec}$ of mirror exposure. The responsiveness then wanes until after $5 \mathrm{~min}$ exposure to the mirror; the duration of gill-cover erection is less than when there is no mirror exposure at all. This waning in responsiveness is in agreement with earlier reports of habituation of aggression in this species (Baenninger, 1966; Clayton \& Hinde, 1968; Figler, 1972; Meliska \& Meliska, 1976; Peeke \& Peeke, 1970), although for most of these earlier studies much longer periods of exposure were needed to demonstrate habituation. The much shorter exposures needed for the reduction of responsiveness in the present experiment might 
have been caused by the mismatch between the preexposed stimulus and the test model.

The facilitating effect of short periods of mirror exposure on displaying to models has not been reported previously, although an apparently similar effect in chaffinches was reported by Hinde (1954, 1960). This effect is unlikely to be due merely to a reorientation of attention by the initial presentation, since the experimenter always waited until the fish was oriented towards the model end of the tank before presenting the model when no mirror presentation was planned. This precaution should at least have ensured that the incremental effect was not a result of chance variations in the position of the fish with respect to the site of model presentation. Also, since fights between pairs of fish escalate gradually (Braddock \& Braddock, 1955; Simpson, 1968), it appears that this warm-up period is not merely an artifact of the situation being used. It appears, then, that the initial increment in responsiveness may be due to a facilitation of aggressive behavior at the expense of other motivational categories. If this is the case, this initial increment might well be given the name "priming," although Clayton and Hinde (1968) refer to a comparable effect as a "warm-up" period.

Although Hinde (1970, pp. 306-308) suggests that such incremental effects are not stimulus-specific, the results of the present study do suggest that the "priming" as well as the habituation were indeed specific to the model most closely resembling the fish's mirror image, at least with the two colors used here. It was only with the blue model that these effects were observed. While the stimulus-specificity of habituation might have been expected (Peeke \& Veno, 1973), specificity of the incremental effect has not previously been reported.

Further support for general stimulus-specificity of priming in this situation must await experiments where red models are used after mirror exposure in blue fish, since there was a significant difference in response to the two models. The blue model elicited far longer durations of gill-cover erection than the green (see Figler, 1972; Lissman, 1932). Such experiments are in progress.

The final effect found in the present study was a change in responsiveness over the course of the experiment. Despite the shortness of the tests, there was significantly less gill-cover erection on the 1st day than on any other of the 6 experimental days, no matter which model was used. Most previous studies have shown a long-term decrease in responsiveness (e.g., Gallagher, Herz, \& Peeke, 1972), even when only relatively short periods of exposure were given on each day (Peeke \& Peeke, 1970). However, Clayton and Hinde (1968) did show that the duration of gill-cover erection (the measure used here) increased over the first $24 \mathrm{~h}$ of continuous mirror exposure, although they did not say whether this increase was statistically significant. The present results show that a (significant) increment can be obtained even with a very short daily test period (1-6 min).

Although the results of this experiment are clearcut for the duration of gill-cover erection, there is as yet no indication of whether similar effects obtain for the various other possible measures of aggressive behavior in fighting fish (Clayton \& Hinde, 1968; Simpson, 1968). Experiments at present in progress are seeking to clarify this question.

\section{REFERENCES}

Assem, J. van Den, \& Molen, J. N. Van DeR. Waning of the aggressive response in the three-spined stickleback upon constant exposure to a conspecific. I. A preliminary analysis of the phenomenon. Behaviour, 1969, 34, 286-323.

BAENNINGER, R. Waning of aggressive motivation in Betta splendens. Psychonomic Science, 1966, 4, 241-242.

BRADDOCK, J. C., \& BRADDOCK, Z. I. Aggressive behaviour among females of the Siamese fighting fish, Betta splendens. Physiological Zoology, 1955, 28, 152-172.

Clayton, F. L., \& Hinde, R. A. The habituation and recovery of aggressive display in Betta splendens. Behaviour, 1968, 30. 96-106.

Figler, M. H. The relation between eliciting stimulus strength and habituation of the threat display in male Siamese fighting fish. Betta splendens. Behaviour, 1972, 42, 63-96.

Gallagher, J. E., Herz, M. J., \& Peeke, H. V. S. Habituation of aggression: The effects of visual social stimuli on behavior between adjacently territorial convict cichlids (Cichlasoma nigrofasciatum). Behavioral Biology, 1972, 7, 359-368.

Hinde, R. A. Factors governing the changes in strength of a partially inborn response, as shown by the mobbing behaviour of the chaffinch (Fringilla coelebs): II. The waning of the response. Proceedings of the Royal Society, Series B, 1954, 142, 331-358.

HiNDE, R. A. Factors governing the changes in strength of a partially inborn response, as shown by the mobbing behaviour of the chaffinch (Fringilla coelebs): III. The interaction of short-term and long-term incremental and decremental effects. Proceedings of the Royal Society, Series B, 1960, 153, 398-420.

Hinde, R. A. Animal behaviour: A synthesis of ethology and comparative psychology (2nd ed.) New York, London: McGrawHill, 1970.

Lissmann, H. W. Die Umwelt des Kampffisches (Betta splendens, Regen). Zeitschrift für vergleichende Physiologie, 1932, 18, 65-111.

Meliska, J. A., \& Meliska C. J. Effects of habituation on threat display and dominance establishment in the Siamese fighting fish, Betta splendens. Animal Learning \& Behavior, 1976, 4, 167-171.

Peeke, H. V. S., \& Peeke, J. C. Habituation of conspecific aggressive responses in the Siamese fighting fish (Betta splendens). Behaviour, 1970, 36, 232-245.

Peeke, H. V. S., \& Veno. A. Stimulus specificity of habituated aggression in the stickleback (Gasterosteus aculeatus). Behavioral Biology, 1973, 8, 427-432.

PeEke, H. V. S., \& VENo, A. Response independent habituation of territorial aggression in the three-spined stickleback (Gasterosteus aculeatus). Zeitschrift fur Tierpsychologie, 1976, 40, 53-58.

Simpson, M. J. A. The display of the Siamese fighting fish, Betta splendens. Animal Behaviour Monographs, 1968, 1, 1-73.

WINER, B. J. Statistical principles in experimental design. New York, London: McGraw-Hill, 1970.

(Received for publication July 15. 1977; revision accepted September 14, 1978.) 